\title{
Molecular epidemiology of vancomycin-resistant Enterococcus faecium strains isolated from haematological malignancy patients in a research hospital in Turkey

\author{
Correspondence \\ S. Kirdar \\ sevin.kirdar@gmail.com
} \\ Received 13 May 2009 \\ Accepted 8 March 2010 \\ S. Kirdar, ${ }^{1}$ A. G. Sener, ${ }^{2}$ U. Arslan ${ }^{3}$ and S. G. Yurtsever ${ }^{2}$

\author{
${ }^{1}$ Department of Microbiology and Clinical Microbiology, Faculty of Medicine, Adnan Menderes \\ University, Aydin, Turkey \\ ${ }^{2}$ Microbiology and Clinical Microbiology Laboratory, Ataturk Training and Research Hospital, Izmir, \\ Turkey \\ ${ }^{3}$ Department of Clinical Microbiology, Selcuklu Faculty of Medicine, Selcuk University, Konya, \\ Turkey
}

\begin{abstract}
Infections and outbreaks of vancomycin-resistant enterococci (VRE) still appear to be rare in Turkey. In the present study, VRE strains isolated during an outbreak in a haematology unit of a training and research hospital in Turkey were typed and their antimicrobial-resistance patterns were characterized by molecular methods. Twelve vancomycin-resistant Enterococcus faecium strains isolated from patients with haematological malignancies were investigated by PCR for the presence of genes encoding resistance to vancomycin, tetracycline, chloramphenicol, gentamicin and erythromycin. Their clonal relationship was evaluated by PFGE and multilocus sequence typing. All strains were resistant to vancomycin and erythromycin, and had the van $A$ and ermB genes, respectively. PFGE was used to determine the presence of two pulsotypes and determine their subtypes. Pulsotype A belonged to sequence type (ST) 17 and pulsotype B belonged to ST 78. All strains with the vanA gene were not the same clone, indicating multiple acquisitions of resistant isolates, even over such a short time period.
\end{abstract}

\section{INTRODUCTION}

Enterococci are part of the normal flora in humans and animals (Huh et al., 2006). These opportunistic pathogens have recently emerged as nosocomial infection agents, especially in patients with haemato-oncological disease and those in intensive care units (Vagnerova et al., 2006). The first vancomycin-resistant enterococci (VRE) were reported from France in 1986 (Leclercq et al., 1988). Reports on VRE colonization and infections in hospitalized patients have rapidly increased in many countries worldwide (Kosack et al., 2009; Huh et al., 2006; Vagnerova et al., 2006; Vilela et al., 2006). Solid-organ-transplant recipients, patients in intensive care units, haematology units or longterm care facilities are all at high risk of VRE infection and colonization (Chlebicki \& Kurup, 2008). In the USA in particular, a remarkable rise in the frequency of VRE has been documented in the intensive care units of hospitals. However, the incidence of vancomycin resistance in enterococci from European hospitals remained at low

Abbreviations: CC, clonal complex; MLST, multilocus sequence typing; NEQAS, National External Quality Assessment Scheme for Microbiology; ST, sequence type; VRE, vancomycin-resistant enterococci. levels during the 1990s and the early 2000s. Recently, a significant increase in the frequency of glycopeptideresistant enterococci (especially Enterococcus faecium) has been reported from a number of European countries such as Germany, Italy, Portugal, Greece and the UK (Klare et al., 2005). Infections and outbreaks with VRE still appear to be rare and information on the prevalence of VRE is limited in Turkey (Colak et al., 2002; Fişgin et al., 2006; Kilic et al., 2006). After the first VRE-infected patient was reported from Ankara, transmission of one epidemic strain has been described in north-western Turkey very recently (Comert et al., 2007).

To date seven different glycopeptide resistance genotypes (VanA-VanE, VanG and VanL) have been described in enterococci (Boyd et al., 2008; Cetinkaya et al., 2000). The VanA and the VanB types are the most commonly encountered forms of acquired glycopeptide resistance (Quintiliani \& Courvalin, 1996), and have the same basic mechanism of resistance (Evers \& Courvalin, 1996). VanA and VanB type strains show inducible resistance, but the level of vancomycin and teicoplanin resistance differs: VanA types have high-level vancomycin and moderatelevel teicoplanin resistance; however, VanB strains show 
various levels of vancomycin resistance but remain susceptible to teicoplanin (Dahl et al., 1999). In the present study, we report the existence of multiple VRE clones with different pulsotypes and subtypes during an outbreak in a haematology unit of a training and research hospital in Turkey between May and October 2006.

\section{METHODS}

Study population and bacterial strains. Ataturk Training and Research Hospital, Izmir, Turkey, is a 1100 bed hospital, with a 15 bed haematology unit. All VRE were isolated from patients with haematological malignancies between May and October 2006. The first documented VRE was isolated in May 2006. After the isolation of five VRE strains from blood samples, a screening programme was initiated. Rectal swab specimens from patients and staff, and environmental samples, were taken. Rectal swab screening was performed three times at weekly intervals. Strains were identified using conventional methods such as Gram staining, the absence of catalase production, resistance to $6.5 \%$ sodium chloride and growth on bile aesculin agar. All VRE strains were confirmed as E. faecium with Phoenix automated microbiology system (BD Diagnostics).

Testing susceptibility to antimicrobials. The susceptibility of the strains to antimicrobials was screened by the disc diffusion method on Mueller-Hinton agar according to Clinical and Laboratory Standard Institute 2005 guidelines for the following antimicrobial agents: penicillin, vancomycin, teicoplanin, ampicillin, ciprofloxacin, gentamicin, erythromycin, tetracycline and chloramphenicol (CLSI, 2005). The antibiotic discs used were from Oxoid. MICs were examined by Phoenix automated microbiology system (BD Diagnostics). E. faecium 8565 (NEQAS) strain was used as an external quality control strain.

DNA isolation and PCR for analysis of the mechanism of resistance. Bacterial DNA was extracted by the boiling method. A colony of bacteria was suspended in $50 \mu \mathrm{l}$ water, boiled for $10 \mathrm{~min}$, placed on ice until chilled and centrifuged at $16000 \mathrm{~g}$ for $1 \mathrm{~min}$ to pellet cell debris. The supernatant was used as a template for PCR (Register \& Yersin, 2005). The presence of vanA, vanB and vanC genes was studied using PCR primers described by Dutka-Malen et al. (1995). The resulting amplification fragments were separated on $2 \%$ agarose gel in $0.5 \times$ TBE buffer $(5.4 \mathrm{~g}$ Tris base, $2.75 \mathrm{~g}$ boric acid, $2 \mathrm{ml}$ 0.5 M EDTA, in $1 \mathrm{~L}$ ). tetM, tetK (Warsa et al., 1996), cat, aac-aph (Kao et al., 2000), ermA, ermB and ermC (Sutcliffe et al., 1996) genes were screened with specific primers.

PFGE. The clonal relationship between vancomycin-resistant strains was studied using PFGE of the genomic DNA (Antonishyn et al., 2000). DNA restricted by SmaI enzyme was separated on an agarose gel using a CHEF DR III apparatus (Bio-Rad laboratories). The running conditions were $6 \mathrm{~V} \mathrm{~cm}^{-1}$, with pulses ranging from 2 to $15 \mathrm{~s}$ for $18 \mathrm{~h}$ at $14{ }^{\circ} \mathrm{C}$. DNA banding patterns were visualized under UV light after staining with ethidium bromide $\left(0.5 \mu \mathrm{g} \mathrm{ml}^{-1}\right)$. The similarity between isolates was determined by visual comparison of isolate band patterns. The interpretation of PFGE results was carried out by eye according to the criteria described by Tenover et al. (1995).

Multilocus sequence typing (MLST). MLST was used to analyse the genetic types of two E. faecium isolates with different pulsotypes. For each isolate from the two pulsotypes, seven housekeeping genes ( $a d k$, atpA, $d d l, g d h, g y d, p u r K$ and $p s t S$ ) were amplified by PCR and all amplicons were sequenced as described by Homan et al. (2002). The sequences were compared with those of the alleles recorded in the database available at the MLST website (http://efaecium.mlst.net) and sequence types (STs) were determined.

\section{RESULTS AND DISCUSSION}

\section{Patients and bacteria}

This study describes an outbreak of VRE strains in a haematology unit of a research hospital. A total of seven patients, aged between 32 and 62 years, were included in this study. The mean age was $45 \pm 11.9$ years. Of the seven patients five were female and two were male. All the VRE strains were isolated from patients with haematological malignancies, all of whom had been hospitalized in the haematology unit. Among the patients with infection, the first VRE strain was identified from a blood culture of a 56year-old female patient at the beginning of the outbreak.

After the isolation of five VRE strains from blood samples, all patients in the haematology unit were screened using rectal swabs and seven more VRE were isolated. Twelve strains were isolated from a total of only seven patients: five patients each contributed two strains from a blood culture and a rectal swab, and two patients each contributed one strain from a rectal swab (Table 1). All strains were confirmed to be E. faecium. The swab specimens of environmental sites and screened staff were not positive based on culturing. No patients died during this outbreak.

\section{Susceptibility pattern and the mechanism of antimicrobial resistance}

The results of testing in vitro susceptibility to antimicrobials for 12 VRE are shown in Table 1. High-level resistance to both glycopeptides (vancomycin and teicoplanin) (with a vancomycin MIC $>16 \mathrm{mg} \mathrm{l}^{-1}$ ) was a feature of all $12 \mathrm{E}$. faecium isolates (VanA phenotype) and this was consistent with the identification of $v a n A$ gene by PCR. Testing of $v a n B$ and $v a n C$ genes was negative for the 12 VRE strains. Our results were similar to those of other European studies (Ergani-Ozcan et al., 2008; Willems et al., 2005; SchmidtHieber et al., 2007; Sample et al., 2002). In most Australian states, several sporadic and outbreak-related strains have been reported. The majority were of the van $\mathrm{B}$ genotype, but E. faecium carrying vanA has also been reported (Bartley et al., 2001; Bell et al., 1998; Worth et al., 2007; Christiansen et al., 2004; Paterson et al., 1996).

All the E. faecium isolates were resistant to most of the drugs tested. All the strains were sensitive to chloramphenicol and tetracycline except one; this one strain was resistant to tetracycline and had the tet $M$ gene. The $12 \mathrm{E}$. faecium had intermediate resistance to chloramphenicol and they were negative for the presence of the cat gene. All E. faecium isolates were resistant to erythromycin and presence of ermB gene was shown by PCR. The gentamicinresistant strains did not carry an aac-aph gene. The pattern of sensitivity to antibiotics for all the E. faecium in the present study is consistent with the notion that resistance to vancomycin is usually accompanied by resistance to other antimicrobial agents, such as penicillin, ampicillin, teicoplanin, erythromycin, ciprofloxacin and gentamicin. 
Table 1. Characteristics of vancomycin-resistant E. faecium cases

MICs $\left(\mathrm{mg} \mathrm{l}^{-1}\right.$ ): teicoplanin, $>16$; vancomycin, $>16$; ciprofloxacin, $>2$; erythromycin, $>4$; gentamicin, $>8$; ampicillin, $>8$; penicillin, $>8$.

\begin{tabular}{|c|c|c|c|c|c|c|c|c|c|}
\hline Case no. & Strain & Sample & $\begin{array}{c}\text { Sex of } \\
\text { patient }\end{array}$ & $\begin{array}{c}\text { Age of } \\
\text { patient (years) }\end{array}$ & $\begin{array}{c}\text { TET } \\
\left(\mathrm{mg} \mathrm{l}^{-1}\right)\end{array}$ & $\begin{array}{c}\text { High level } \\
\text { GEN (mg l-1) }\end{array}$ & Genotype & Pulsotype & ST \\
\hline \multirow[t]{2}{*}{1} & 1 & Blood & $\mathrm{F}$ & 56 & $\leqslant 0.5 \mathrm{~S}$ & $>500 \mathrm{R}$ & vanA & B & \\
\hline & 2 & Rectal swab & & & $\leqslant 0.5 \mathrm{~S}$ & $>500 \mathrm{R}$ & vanA & B & \\
\hline \multirow[t]{2}{*}{2} & 3 & Blood & $\mathrm{F}$ & 34 & $\leqslant 0.5 \mathrm{~S}$ & $>500 \mathrm{R}$ & $\operatorname{van} A$ & B1 & \\
\hline & 4 & Rectal swab & & & $\leqslant 0.5 \mathrm{~S}$ & $>500 \mathrm{R}$ & vanA & B2 & \\
\hline \multirow[t]{2}{*}{3} & 5 & Blood & $\mathrm{F}$ & 62 & $\leqslant 0.5 \mathrm{~S}$ & $\leqslant 500 \mathrm{~S}$ & vanA & A & 17 \\
\hline & 6 & Rectal swab & & & $\leqslant 0.5 \mathrm{~S}$ & $>500 \mathrm{R}$ & vanA & A & \\
\hline \multirow[t]{2}{*}{4} & 7 & Blood & M & 35 & $\leqslant 0.5 \mathrm{~S}$ & $>500 \mathrm{R}$ & $\operatorname{van} A$ & A1 & \\
\hline & 8 & Rectal swab & & & $\leqslant 0.5 \mathrm{~S}$ & $>500 \mathrm{R}$ & $\operatorname{van} A$ & A2 & \\
\hline \multirow[t]{2}{*}{5} & 9 & Blood & $\mathrm{F}$ & 44 & $\leqslant 0.5 \mathrm{~S}$ & $>500 \mathrm{R}$ & $\operatorname{van} A$ & B & 78 \\
\hline & 10 & Rectal swab & & & $>4$ & $>500 \mathrm{R}$ & $\operatorname{van} A$ & B & \\
\hline 7 & 11 & Rectal swab & $\mathrm{F}$ & 32 & $\leqslant 0.5 \mathrm{~S}$ & $>500 \mathrm{R}$ & vanA & A2 & \\
\hline 8 & 12 & Rectal swab & M & 52 & $\leqslant 0.5 \mathrm{~S}$ & $>500 \mathrm{R}$ & $\operatorname{van} A$ & A & \\
\hline
\end{tabular}

F, Female; GEN, gentamicin; M, male; R, resistant; S, sensitive; TET, tetracycline.

All strains, except one, remained sensitive to chloramphenicol and tetracycline as has been reported in other studies.

\section{PFGE and MLST}

In this outbreak, a main pulsotype $A$ and minor pulsotype $B$ with their subtypes were determined among 12 VRE isolates by PFGE. Six isolates belonged to pulsotype group $\mathrm{A}$ (3A, 1A1 and 2A2 subtypes) and other isolates were from group B (4B, 1B1 and 1B2 subtypes) (Fig. 1).

MLST was performed for two E. faecium isolates with different pulsotypes. The allelic profile of pulsotype A was: atpA 1, ddl 1, gdh 1, purK 1, gyd 1, pstS 1, adk 1, thus corresponding to ST 17. Pulsotype B belonged to ST 78 (atpA 15, ddl 1, gdh 1, purK 1, gyd 1, pstS 1, adk 1). Both ST 17 and ST 78 belong to the clonal complex-17 (CC-17) lineage, which is the cause of most of the nosocomial VRE outbreaks worldwide. The hospital-adapted CC-17 has rapidly spread globally during the last two decades. There is a large complex of genetically related STs: ST 22 is the primary founder and within ST 22, ST 17 represents an important secondary founder of a distinct branch designated CC-17 (Ergani-Ozcan et al., 2008). Nosocomial outbreaks of ST 78, belonging to CC-17, have been described in Korea and in Europe, including in Germany and Italy (Klare et al., 2005). Ergani-Ozcan et al. (2008) found $E$. faecium isolates, with the vanA genotype, a main pulsotype (A) and three minor pulsotypes $(B, C, D)$ in a nosocomial outbreak in a paediatric unit at a Turkish university hospital. The epidemic strain A was ST 31, and the minor strain D was ST 18. ST 31 and ST 18 are both in CC-17. We found that all VRE isolates of the present outbreak were similar to the CC-17 designated by ErganiOzcan et al. (2008). Rapid diagnosis of CC-17 strains is very important as it may help to control spreading. In many European countries, a relatively large community reservoir of VRE exists as a result of the massive use of the antimicrobial drug avoparcin as a growth promoter, while the prevalence of hospital-adapted (CC-17) VRE is, in general, much lower (Willems et al., 2005)

To control this outbreak, the patients and carriers were screened, and all hygiene measures recommended were taken according to international guidelines. Staff education and strict implementation were monitored by the Hospital Infection Control Committee (Ataturk Training and Research Hospital). In the haematological unit in our study

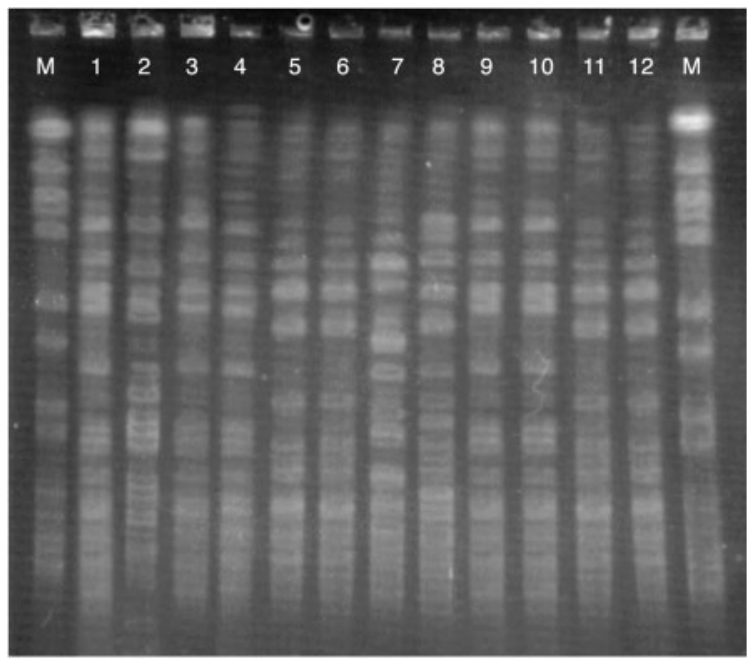

Fig. 1. PFGE of Smal-digested genomic DNA from vancomycinresistant $E$. faecium isolates from different patients. Lanes 1-12, isolates from patients: lanes 5,6 and 12 , pulsotype $A$; lane 7 , pulsotype $A 1$; lanes 8 and 11, pulsotype A2; lanes 1, 2, 9 and 10, pulsotype $\mathrm{B}$; lane 3 , pulsotype $\mathrm{B} 1$; lane 4 , pulsotype $\mathrm{B} 2 . \mathrm{M}$, Marker. 
all patients were separated and treated with linezolid, and the outbreak was controlled by limiting new admissions to the unit. The presence of multiple antimicrobial resistance E. faecium obligates the clinician to choose appropriate treatment. In conclusion, our data indicated that all strains with the vanA gene were not the same clone indicating multiple acquisitions of resistant isolates, even over such a short time period, and the strains belonged to an internationally disseminated lineage.

\section{ACKNOWLEDGEMENTS}

Thanks to Dr Bülent Bozdoğan for his valuable contributions.

\section{REFERENCES}

Antonishyn, N. A., McDonald, R. R., Chan, E., Horsman, G., Woodmansee, C. E., Falk, P. S. \& Mayhall, C. G. (2000). Evaluation of fluorescence-based amplified fragment length polymorphism analysis for molecular typing in hospital epidemiology: comparison with pulsed-field gel electrophoresis for typing strains of vancomycinresistant Enterococcus faecium. J Clin Microbiol 38, 4058-4065.

Bartley, P. B., Schooneveldt, J. M., Looke, D. F., Morton, A., Johson, D. W. \& Nimmo, G. R. (2001). The relationship of a clonal outbreak of Enterococcus faecium vanA to methicillin-resistant Staphylococcus aureus incidence in an Australian hospital. J Hosp Infect 48, 43-54.

Bell, J. M., Paton, J. C. \& Turnidge, J. (1998). Emergence of vancomycin resistant enterococci in Australia: phenotypic and genotypic characteristics of isolates. J Clin Microbiol 36, 2187-2190.

Boyd, D. A., Willey, B. M., Fawcett, D., Gillani, N. \& Mulvey, M. R. (2008). Molecular characterization of Enterococcus faecalis N06-0364 with low-level vancomycin resistance harboring a novel D-Ala-D-Ser gene cluster, vanL. Antimicrob Agents Chemother 52, 2667-2672.

Cetinkaya, Y., Falk, P. \& Mayhal, C. G. (2000). Vancomycin-resistant enterococci. Clin Microbiol Rev 13, 686-707.

Chlebicki, M. P. \& Kurup, A. (2008). Vancomycin-resistant enterococcus: a review from a Singapore perspective. Ann Acad Med Singapore 37, 861-869.

Christiansen, K.J., Tibbett, P.A., Beresford, W., Pearman, J. W., Lee, R. C., Coombs, G. W., Kay, I. D., O'Brien, F. G., Palladino, S. \& other authors (2004). Eradication of a large outbreak of a single strain of vanB vancomycin-resistant Enterococcus faecium at a major Australian teaching hospital. Infect Control Hosp Epidemiol 25, 384-390.

CLSI (2005). Performance Standards for Antimicrobial Susceptibility Testing, 15th international supplement, M100-S15. Wayne, PA: Clinical and Laboratory Standards Institute.

Colak, D., Naas, T., Gunseren, F., Fortineau, N., Ogunc, D., Gultekin, M. \& Nordmann, P. (2002). First outbreak of vancomycin-resistant enterococci in a tertiary hospital in Turkey. J Antimicrob Chemother 50, 397-401.

Comert, F. B., Kulah, C., Aktas, E., Ozlu, N. \& Celebi, G. (2007). First isolation of vancomycin-resistant enteroccoci and spread of a single clone in a university hospital in northwestern Turkey. Eur J Clin Microbiol Infect Dis 26, 57-61.

Dahl, K. H., Simonsen, G. S., Olsvik, O. \& Sundsfiord, A. (1999). Heterogeneity in the $v a n B$ gene cluster of genomically diverse clinical strains of vancomycin-resistant enterococci. Antimicrob Agents Chemother 43, 1105-1111.

Dutka-Malen, S., Evers, S. \& Courvalin, P. (1995). Detection of glycopeptide resistance genotypes and identification to the species level of clinically relevant enterococci by PCR. J Clin Microbiol 33, 2427.

Ergani-Ozcan, A., Naas, T., Baysan, B. O., Ogunc, D., Inan, D., Colak, D. \& Nordmann, P. (2008). Nosocomial outbreak of vancomycin-resistant Enterococcus faecium in a paediatric unit at a Turkish university hospital. J Antimicrob Chemother 61, 1033-1039.

Evers, S. \& Courvalin, P. (1996). Regulation of VanB-type vancomycin resistance gene expression by the $\operatorname{VanS}_{\mathrm{B}}-\mathrm{VanR}_{\mathrm{B}}$ two-component regulatory system in Enterococcus faecalis V583. J Bacteriol 178, 13021309.

Fişgin, N. T., Darka, O., Fişgin, T., Hepsert, S., Coban, A. Y. \& Elli, M. (2006). Surveillance study of vancomycin resistant enterococci in pediatric haematology and oncology patients. Mikrobiyol Bul 40, 245250 (in Turkish).

Homan, W. L., Tribe, D., Poznanski, S., Li, M., Hogg, G., Spalburg, E., Van Embden, J. D. A. \& Willems, R. J. L. (2002). Multilocus sequence typing scheme for Enterococcus faecium. J Clin Microbiol 40, 19631971.

Huh, J. Y., Lee, W. G. \& Jin, H. Y. (2006). Molecular characterization of vancomycin-resistant enterococci from clinical and surveillance specimens. Infect Control Hosp Epidemiol 27, 1076-1080.

Kao, S. J., You, I., Clewell, D. B., Donabedian, S. M., Zervos, M. J., Petrin, J., Shaw, K. J. \& Chow, J. W. (2000). Detection of the high-level aminoglycoside resistance gene $a p h\left(2^{\prime \prime}\right)-I b$ in Enterococcus faecium. Antimicrob Agents Chemother 44, 2876-2879.

Kilic, A., Senses, Z., Aydoğan, H. \& Başustaoglu, A. (2006). Molecular analysis of vancomycin-resistant enterococci isolated from clinical samples. Mikrobiyol Bul 40, 295-299 (in Turkish).

Klare, I., Konstabel, C., Berling, M. S., Werner, G., Strommenger, B., Kettlitz, C., Borgmann, S., Schulte, B., Jonas, D. \& other authors (2005). Spread of ampicillin/vancomycin-resistant Enterococcus faecium of the epidemic-virulent clonal complex-17 carrying the genes esp and hyl in German hospitals. Eur J Clin Microbiol Infect Dis 24, 815-825.

Kosack, A., Riedel, E., Kiehn, T. E., Small, T. N., Wexler, L. H. \& Dunkel, I. J. (2009). Vancomycin-resistant enterococcus in pediatric oncology patients: an analysis of potential consequences of colonization and infection. Pediatr Blood Cancer 52, 300-302.

Leclercq, R., Derlot, E., Duval, J. \& Courvalin, P. (1988). Plasmidmediated resistance to vancomycin and teicoplanin in Enterococcus faecium. N Engl J Med 319, 157-161.

Paterson, D., Jennings, A., Allen, A., Sherlock, K. \& Whitby, M. (1996). Isolation of vancomycin-resistant enterococci in Queensland, case 1. Commun Dis Intell 20, 400-401.

Quintiliani, R., Jr \& Courvalin, P. (1996). Characterization of Tn1547, a composite transposon flanked by the IS 16 and IS256-like elements, that confers vancomycin resistance in Enterococcus faecalis BM4281. Gene 172, 1-8.

Register, K. B. \& Yersin, A. G. (2005). Analytical verification of a PCR assay for identification of Bordetella avium. J Clin Microbiol 43, 55675573.

Sample, M. L., Gravel, D., Oxley, C., Toye, B., Garber, G. \& Ramotar, K. (2002). An outbreak of vancomycin-resistant enterococci in a hematology-oncology unit: control by patient cohorting and terminal cleaning of the environment. Infect Control Hosp Epidemiol 23, 468470 .

Schmidt-Hieber, M., Blau, I. W., Schwartz, S., Uharek, L., Weist, K., Eckmanns, T., Jonas, D., Rüden, H., Thiel, E. \& other authors (2007). Intensified strategies to control vancomycin-resistant enterococci in immunocompromised patients. Int J Hematol 86, 158162. 
Sutcliffe, J., Grebe, T., Tait-Kamradt, A. \& Wondrack, L. (1996). Detection of erythromycin-resistant determinants by PCR. Antimicrob Agents Chemother 40, 2562-2566.

Tenover, F. C., Arbeit, R. D., Goering, R. V., Mickelsen, P. A., Murray, B. E., Persing, D. H. \& Swaminathan, B. (1995). Interpreting chromosomal DNA restriction patterns produced by pulsed-field gel electrophoresis: criteria for bacterial strain typing. J Clin Microbiol 33, 2233-2239.

Vagnerova, I., Sauer, P., Kolar, M., Slepickova, S., Hubacek, J., Faber, E., Raida, L. \& Papajik, T. (2006). Sources and pathways of spread of vancomycin-resistant enterococci in hemato-oncological patients. Biomed Pap Med Fac Univ Palacky Olomouc Czech Repub 150, 117-120.

Vilela, M. A., Souza, S. L., Palazzo, V. C. I., Ferreira, J. C., Morais, M. A., Darini, A. L. \& Morais, M. M. (2006). Identification and molecular characterization of Van A-type vancomycin-resistant Enterococcus faecalis in northeast of Brazil. Mem Inst Oswaldo Cruz 101, 715-719.

Warsa, U. C., Nonoyama, M., Ida, T., Okamoto, R., Okubo, T., Shimauchi, C., Kuga, A. \& Inoue, M. (1996). Detection of tet $(\mathrm{K})$ and tet $(\mathrm{M})$ in Staphylococcus aureus of Asian countries by the polymerase chain reaction. J Antibiot (Tokyo) 49, 1127-1132.

Willems, R. J., Top, J., Van Santen, M., Robinson, D. A., Coque, T. M., Baquero, F., Grundmann, H. \& Bonten, M. J. (2005). Global spread of vancomycin-resistant Enterococcus faecium from distinct nosocomial genetic complex. Emerg Infect Dis 11, 821-828.

Worth, L. J., Thursky, K. A., Seymour, J. F. \& Slavin, M. A. (2007). Vancomycin-resistant Enterococcus faecium infection in patients with hematologic malignancy: patients with acute myeloid leukemia are at high-risk. Eur J Haematol 79, 226-233. 